\title{
A Study on the Performance of the Convective Heat Transfer of Hybrid Smart Mushroom Cultivation Equipment
}

\author{
Jae-Hwan Son ${ }^{1}$, Dong-Hyun $\mathrm{Cho}^{2}$ and Kyu-Dong $\mathrm{Nah}^{3}$ \\ ${ }^{1}$ The Daegu Mechatronics \& Materials Institute, 32, SeongSeogondan-ro 11-gil, \\ Dalseo-gu, Daegu, 42714, Rep. of Korea \\ ${ }^{2}$ The University of Daejin, 1007, Hogukro, Pocheonsi, Gyeinggodo, 11159, Rep. \\ of Korea, chodh@daejin.ac.kr \\ ${ }^{3}$ HNL Co., Ltd, 20-6, Daesilyeoknam-ro 2-gil, Dasa-eup, Dalseong-gun, Daegu, \\ 42939, Rep. of Korea
}

\begin{abstract}
The hybrid smart mushroom cultivation equipment's internal fluid was assumed to be air. Four each FCUs and FANs were assumed to be on the left and on the right and one each FCU and FAN were assumed to be on the front for forced flows. Four cases where the FCUs and FANs were installed high or low were analyzed. To analyze the smart farm at room temperature, the internal initial temperature was set to $10{ }^{\circ} \mathrm{C}$ and it was assumed that air at $15^{\circ} \mathrm{C}$ would flow in through the FCUs at $0.5 \mathrm{~m} / \mathrm{s}$ and flow out through the FANs. In addition, the internal temperature of smart mushroom growing facility was assumed to be optimal when it is constant in a range of $12 \sim 18^{\circ} \mathrm{C}$ and the panels were assumed to be insulated. Analyses were conducted for four seasons too. By stably realizing consistent environmental management, smart mushroom cultivation equipment optimum conditions not only save the effort for ventilation repeated everyday but also enable the management of ventilation at the optimum thereby enabling high quality production. The present study is intended to examine sandwich insulation panel type smart farm systems through flow analyses. The positions of FCUs and FANs that are in charge of air inflows/outflows were adjusted to smoothen the air flows between the multiple array mushroom beds in four lines of seven layers and prevent environmental differences between upper and lower mushroom beds. The standard deviation of the smart mushroom growing facility where FCUs and FANs were positioned low was the smallest amounting to 0.298. Therefore, this smart mushroom cultivation was judged to be the optimum model because the temperatures around the shelves inside the smart mushroom cultivation equipment became the most evenly distributed. Select 635 points around the shelf in the inside where flows occur to determine temperature results and check the mean and standard deviation. The standard deviation refers to the average value of the differences (deviations) between all values from the mean. The larger the standard deviation is, the more the value deviates from the mean. Therefore, the standard deviation represents the degree of scattering of the observed values. Therefore, the smaller the standard deviations of the model, the more uniform the temperature distribution
\end{abstract}

Keywords: Mushroom cultivation equipment, Information and Communications Ttechnology, Performance, Smart Facility, Convective Heat transfer

\section{Introduction}

Although the energy consumption in the agricultural sector accounts for only $1.8 \%$ of the national energy consumption, the importance of energy in agricultural product production is very high. In particular, energy inputs have been increasing due to the expansion of controlled horticulture and the progress of mechanization ${ }^{(1)}$. In particular, in 
the case of thermophilic crops, since the ratio of energy used has been increasing remarkably over the last several years, energy saving is required. Although new \& renewable energy that can substitute for energy saving facilities and fossil fuels for energy saving have been recently developed and supplied, the extent of supply has been insignificant. Therefore, the reasons why the supply cannot progress smoothly have been investigated and measures to increase the supply have been sought for ${ }^{(2-5)}$. In the current situation where fossil fuels may be exhausted globally and the prospect of international oil prices is uncertain, the necessity to reduce operating costs by reducing the dependence on fossil fuels or enhancing the efficiency of fuels has been coming to the fore ${ }^{(6)}$. In addition, as the situation where carbon emissions should be reduced has come, in the agricultural sector too, pressure toward the reduction of energy consumption has been increasing and this has become a constraint factor against the enhancement of agricultural productivity. ${ }^{(7 \sim 10)}$. In addition, for energy cost saving and carbon emission reduction in response to global warming, the energy use structure in the agricultural sector should be re-reviewed in order to take measures such as increasing energy saving facilities that can enhance the efficiency of energy and increasing the use of new \& renewable energy that can substitute for fossil fuels. ${ }^{(11)}$. Kim et a1. ${ }^{(12)}$ conducted a study on the effects of changes in the amount of ventilation in mushroom cultivation houses on the growth and development of mushrooms and analyzed basic data. Youn et a1 ${ }^{(13)}$ analyzed the heat transfer efficiency of the cross sections of vertical closed heat exchangers through numerical analysis that provides basic data on the effects of changes in the temperature and flow velocity on smart farms. They derived results indicating that the flow velocity of the air glowing in heat exchangers and temperature distributions are variables that have large effects on heat transfer efficiency. However, the results of previous studies have not reported the temperature distribution characteristics of energy farm hybrid small composite smart farms. Hybrid smart mushroom cultivation equipment realize stable and consistent environmental management so that not only the effort for ventilation repeated everyday can be saved but also the amount of ventilation can be managed at the optimum thereby enabling high quality production ${ }^{(14)}$. The present study is intended to analyze air flows in hybrid smart mushroom cultivation equipment and investigate the temperature distribution characteristics with a view to implementing optimum hybrid smart mushroom cultivation equipment. In addition, the present study is also intended to adjust the positions of FCUs and FANs that are in charge of air inflows/outflows to smoothen the air flows between the multiple array mushroom beds in four lines of seven layers with a view to implementing uniform environments in the upper and lower mushroom beds. Hybrid smart mushroom cultivation equipment was implemented to produce uniform and high quality mushroom by controlling temperature, humidity and environment optimized for mushroom production.

\section{Modelong of Mushroom Growing Facility}

Figure 1 shows the entire smart farm analysis model and the inside shape of the model. As shown in Figure 1 and 2, the internal fluid of the smart farm was assumed to be air and the internal beam material and its material properties are as shown in Table 1. To analyze smart mushroom cultivation equipment at room temperature, the internal initial temperature was set to $10^{\circ} \mathrm{C}$ and it was assumed that air at $15^{\circ} \mathrm{C}$ came in through the FCU(Fan Coil Unit) and $0.5 \mathrm{~m} / \mathrm{s}$ and went out through the FANs. In addition, the internal temperature of smart mushroom cultivation equipment was assumed to be optimal when it is constant in a range of $12 \sim 18^{\circ} \mathrm{C}$ and the panels were assumed to be insulated. Analyses were conducted for four seasons too. 


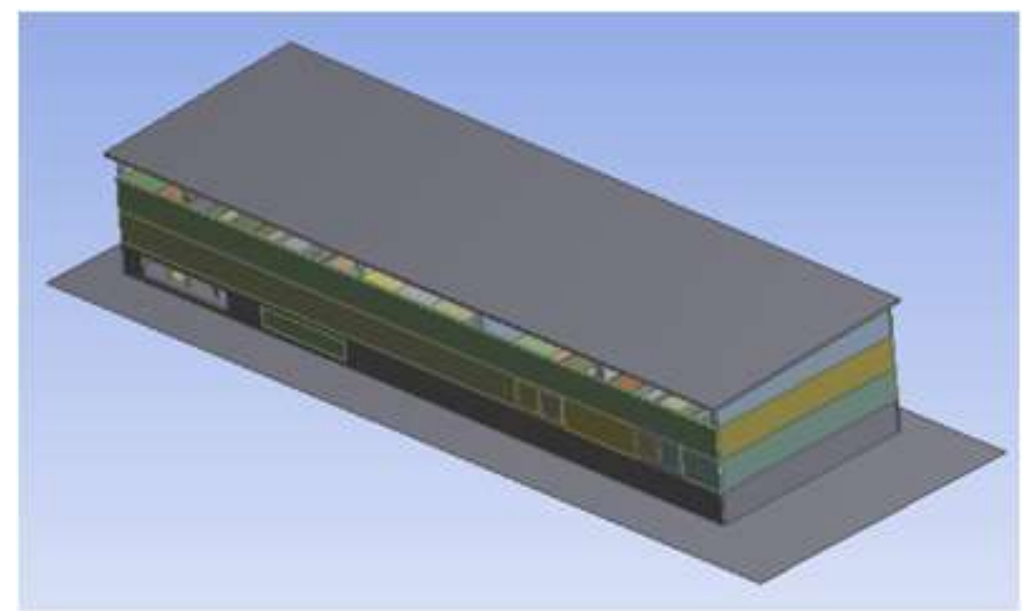

(a) Smart Mushroom Cultivation Equipment Model (Entire Model)

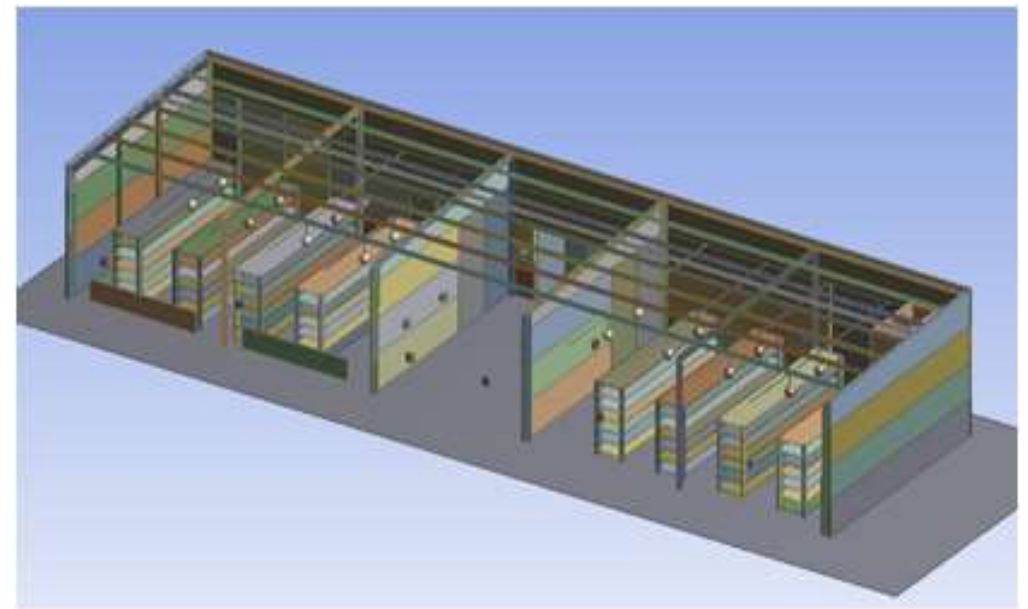

(b) Smart Mushroom Cultivation Equipment Model (Internal Shape)

\section{Figure 1. Smart Mushroom Cultivation Equipment Analysis Model}

Figure 2 shows the parts for flow analysis of the actual model and analysis model of the smart mushroom cultivation equipment. As shown in Figure 2, the air layers inside the smart mushroom cultivation equipment were analyzed and since the model was bilaterally symmetric, only the left part was modeled.

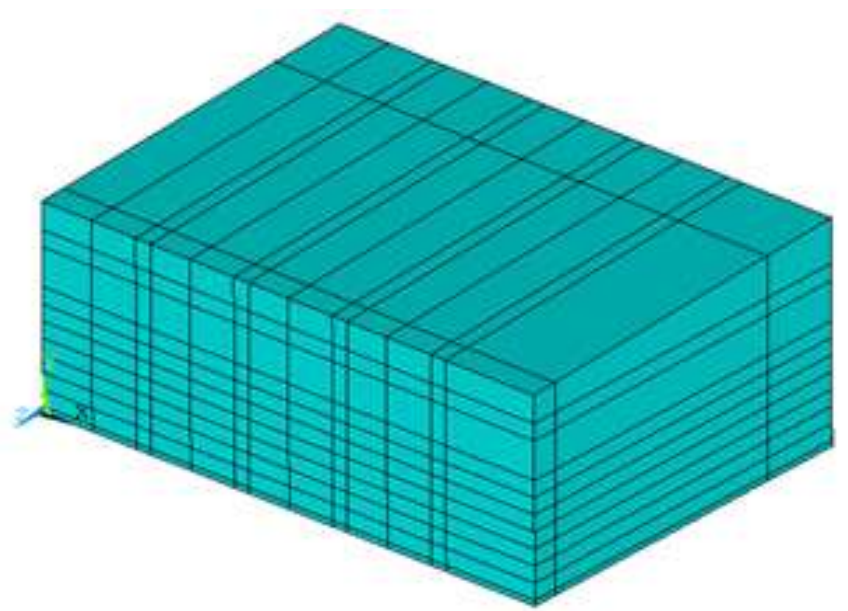

(a) Analysis Model of Mushroom Cultivation Equipment 


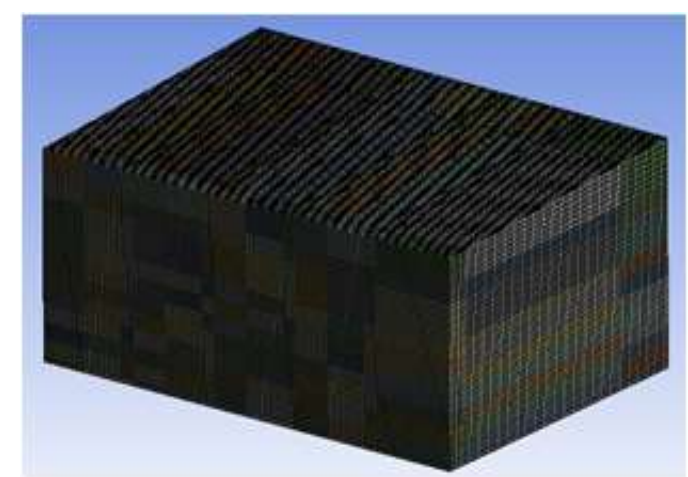

(b) Finite Element Model of Mushroom Cultivation Equipment

\section{Figure 2. Actual Model and Analysis Model of the Smart Mushroom Cultivation Equipment}

Table 1 shows the material properties of air used in the flow analysis and the material properties of steel used in the structural analysis of mushroom cultivation equipment.

Table 1. Material Properties of the Fluid (Air)

\begin{tabular}{c|c|c|c}
\hline Fluid & Density $\left[\mathrm{kg} / \mathrm{m}^{3}\right]$ & Molar Mass[kg/kmol] & $\begin{array}{c}\text { Specific Heat } \\
\text { Capacity }[\mathrm{Jkg} /(\mathrm{kg} \cdot \mathrm{K})]\end{array}$ \\
\hline Air & 1.185 & 28.96 & 343 \\
\hline
\end{tabular}

Table 2. Material Properties of the Structural Steel

\begin{tabular}{c|c|c|c|c}
\hline $\begin{array}{c}\text { Material } \\
\text { property model }\end{array}$ & $\begin{array}{c}\text { Density } \\
{\left[\mathrm{kg} / \mathrm{m}^{3}\right]}\end{array}$ & $\begin{array}{c}\text { Modulus of elasticity } \\
{[\mathrm{MPa}]}\end{array}$ & $\begin{array}{c}\text { Yield } \\
\text { strength[MPa] }\end{array}$ & $\begin{array}{c}\text { Poisson's } \\
\text { ratio }\end{array}$ \\
\hline $\begin{array}{c}\text { Mushroom } \\
\text { cultivation house }\end{array}$ & 7850 & $210 \times 103$ & 250 & 0.3 \\
\hline
\end{tabular}

As shown in Figure 3, four each FCUs and FANs were assumed to be on the left and on the right and one each FCU and FAN were assumed to be on the front for forced flows and four cases where the FCUs and FANs were installed high or low were analyzed. As shown in Figure 3, the analysis was conducted under the condition that air at $15^{\circ} \mathrm{C}$ would flow in through the FCUs at $0.5 \mathrm{~m} / \mathrm{s}$ and flow out through the FAN. 


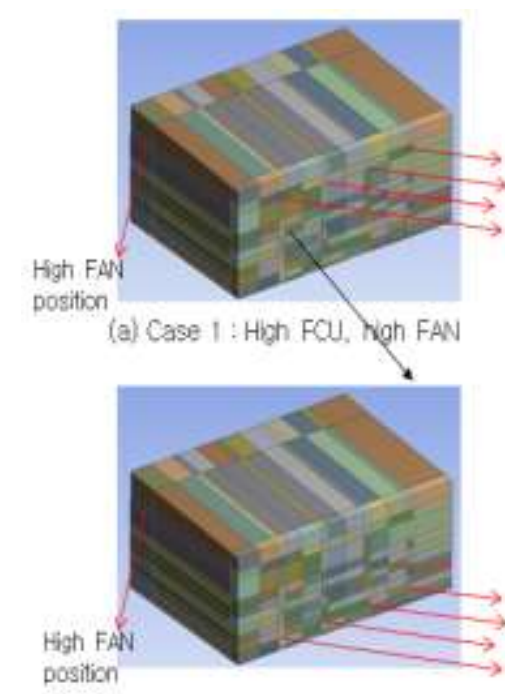

(c) Case 3: High FCU, Hgh FAN

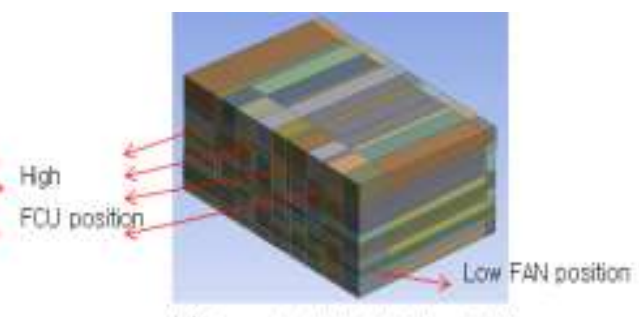

(b) Case 2 : High FOU, bW FAN

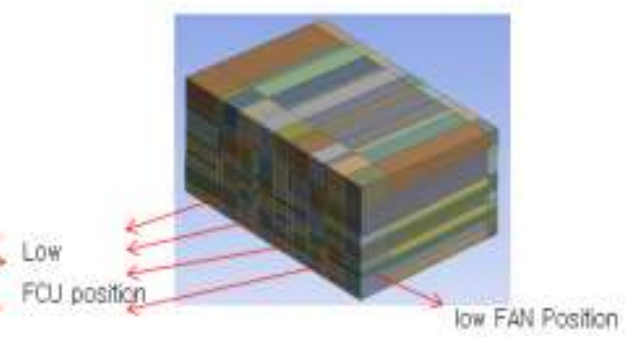

(d) Case 4 : High FOU, bw FAN

Figure 3. Analysis Conditions of Mushroom Cultivation Equipment

\section{Convective Heat Transfer Characterists of Mushroom Cultivation Equipment}

Figure 4 shows the flow characteristics of Case 1 and Figure 5 shows the heat transfer characteristics of Case 1. As shown in Figure 4, the air blown by the FCUs flows inside to go out through the FANs. The velocity shows a distribution in a range of $0 \sim 0.84 \mathrm{~m} / \mathrm{s}$. As shown in Figure 5, the temperatures are high when the air is blown by the FCUs and heat was transferred to the entire space through convection. The temperatures showed a distribution in a range of $11.6 \sim 14.5^{\circ} \mathrm{C}$

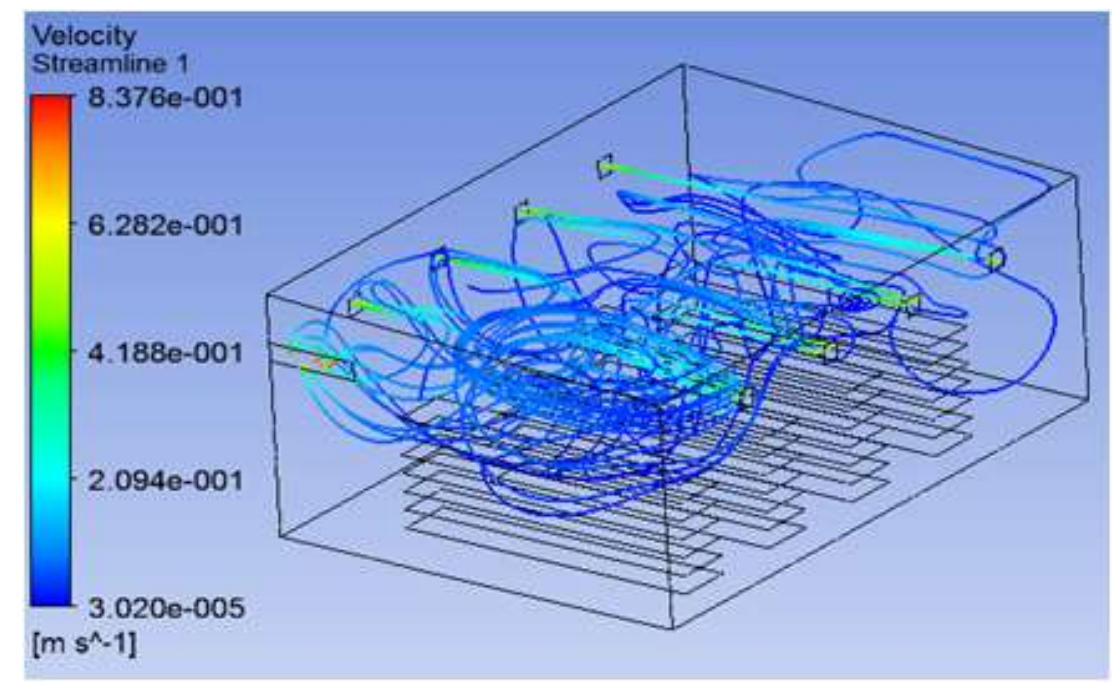

(a) Streamline distribution (diagonal view) 


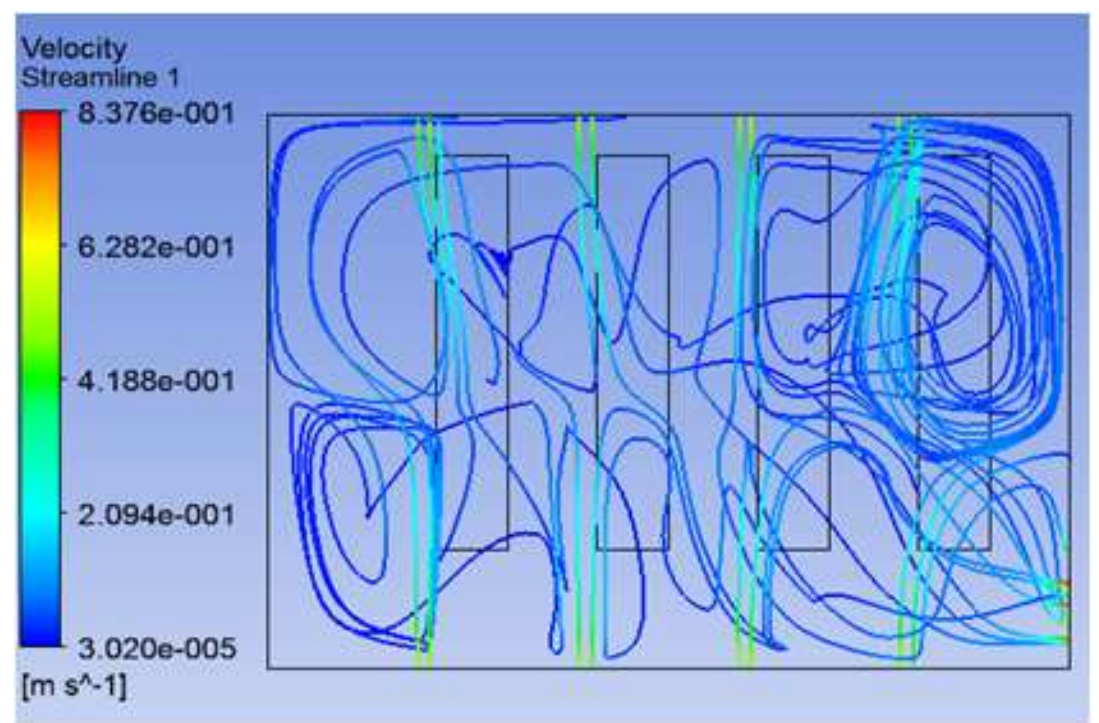

(b) Streamline distribution (top view)

\section{Figure 4. Flow Characteristics of Case 1}

Figure 6 shows the flow characteristics of Case 2 and Figure 7 shows the heat transfer characteristics of Case 2. As shown in Figure 6, the air blown by the FCUs flows inside to go out through the FANs. The velocity shows a distribution in a range of $0 \sim 0.84 \mathrm{~m} / \mathrm{s}$. As shown in Figure 7, the temperatures are high when the air is blown by the FCUs and heat was transferred to the entire space through convection. The temperatures showed a distribution in a range of $12.1 \sim 14.6^{\circ} \mathrm{C}$.

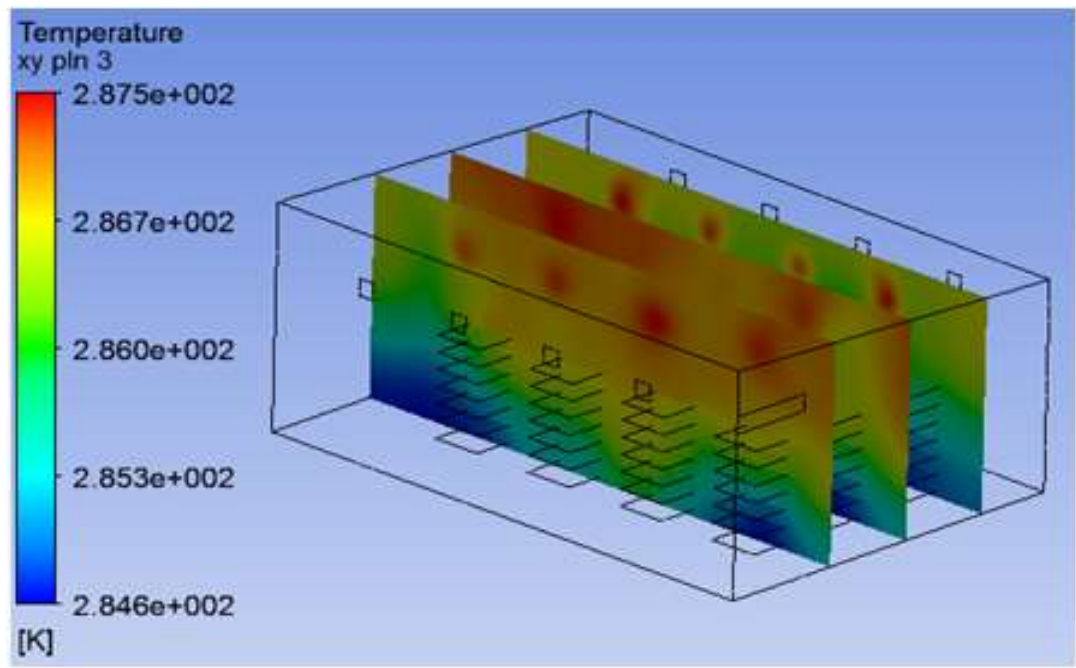

(a) Cross-sectional Temperature Distribution 


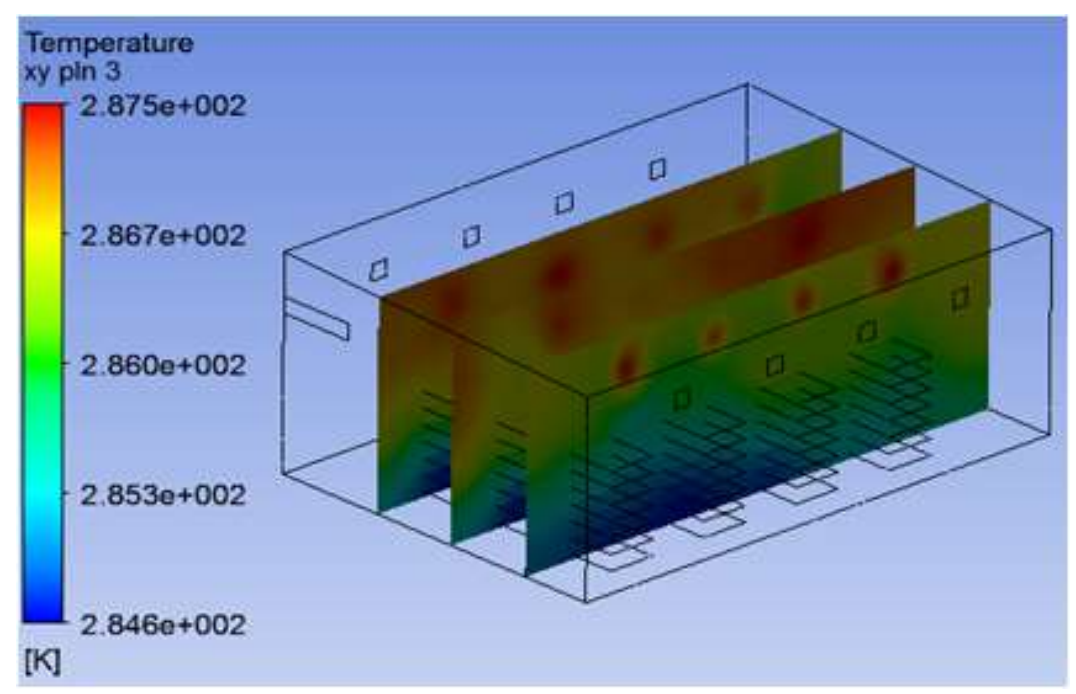

(b) Cross-sectional Temperature Distribution

Figure 5. Heat Transfer Characteristics of Case 1

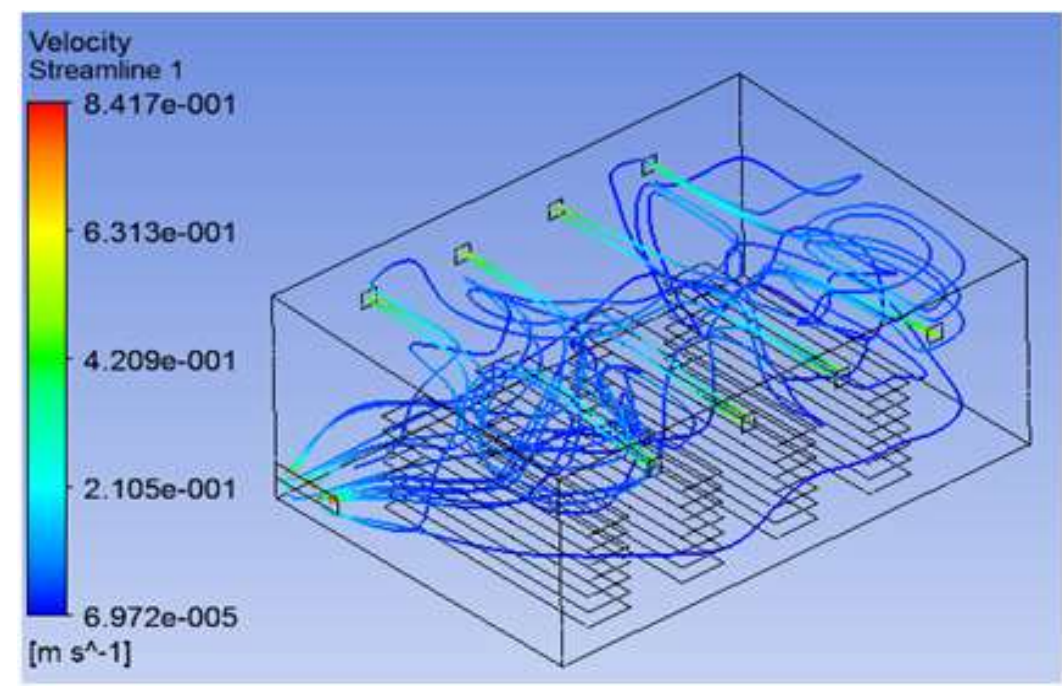

(a) Streamline Distribution (Diagonal View)

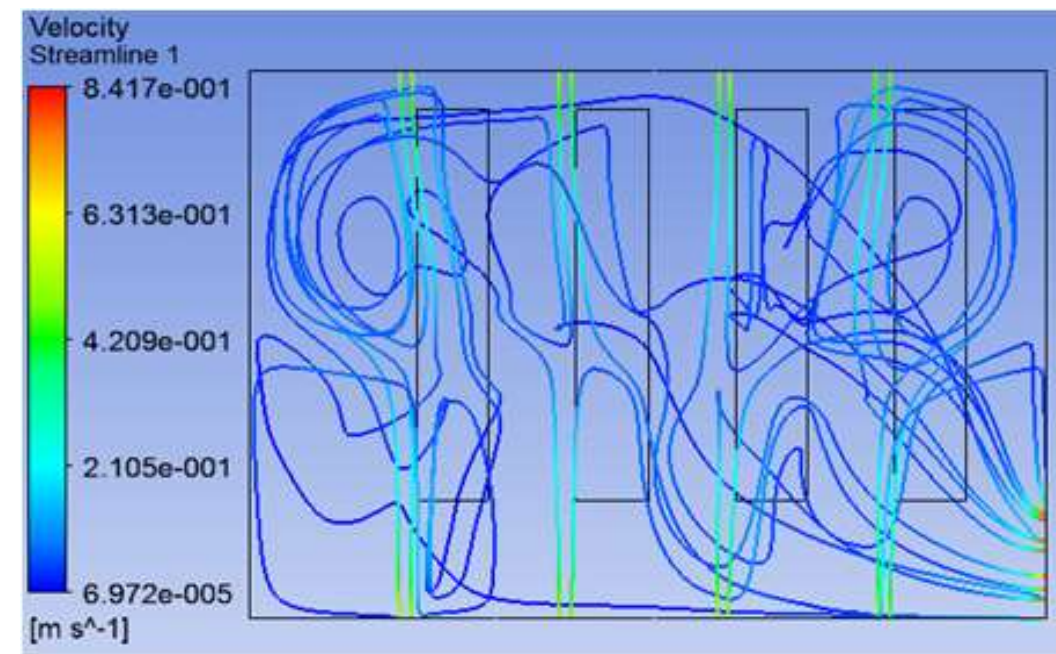

(b) Streamline Distribution (Top View)

Figure 6. Flow Characteristics of Case 2 


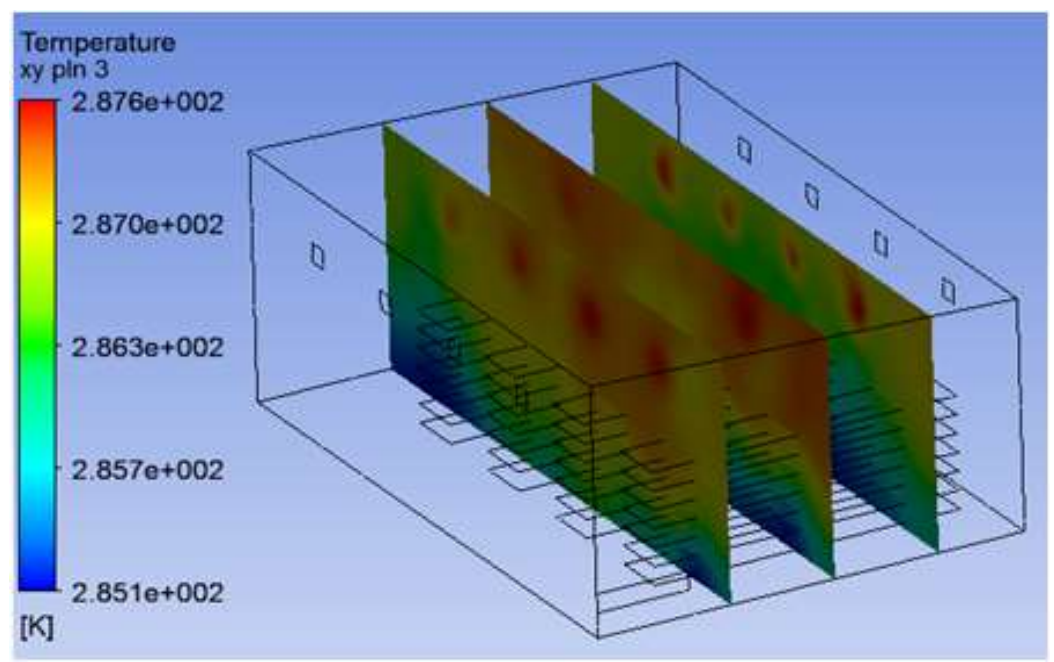

(a) Cross-sectional temperature distribution

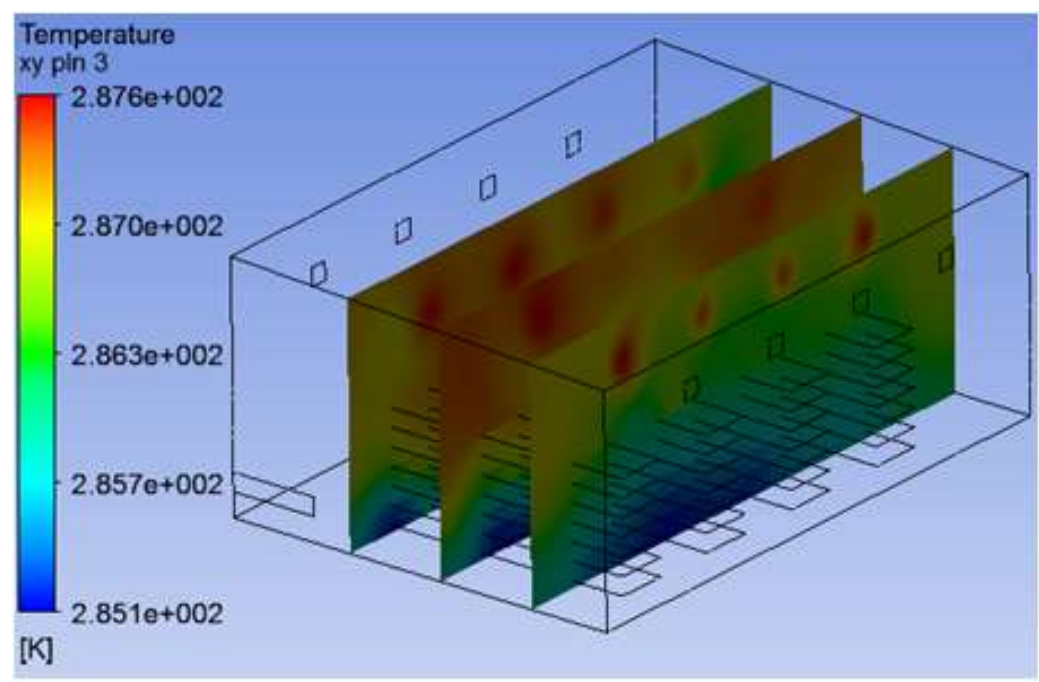

(b) Cross-sectional temperature distribution

Figure 7. Heat Transfer Characteristics of Case 2

Figure 8 shows the flow characteristics of Case 3 and Figure 9 shows the heat transfer characteristics of Case 3. As shown in Figure 8, the air blown by the FCUs flows inside to go out through the FANs. The velocity shows a distribution in a range of $0 \sim 0.84 \mathrm{~m} / \mathrm{s}$. As shown in Figure 9, the temperatures are high when the air is blown by the FCUs and heat was transferred to the entire space through convection. The temperatures showed a distribution in a range of $12.6 \sim 14.5^{\circ} \mathrm{C}$. 


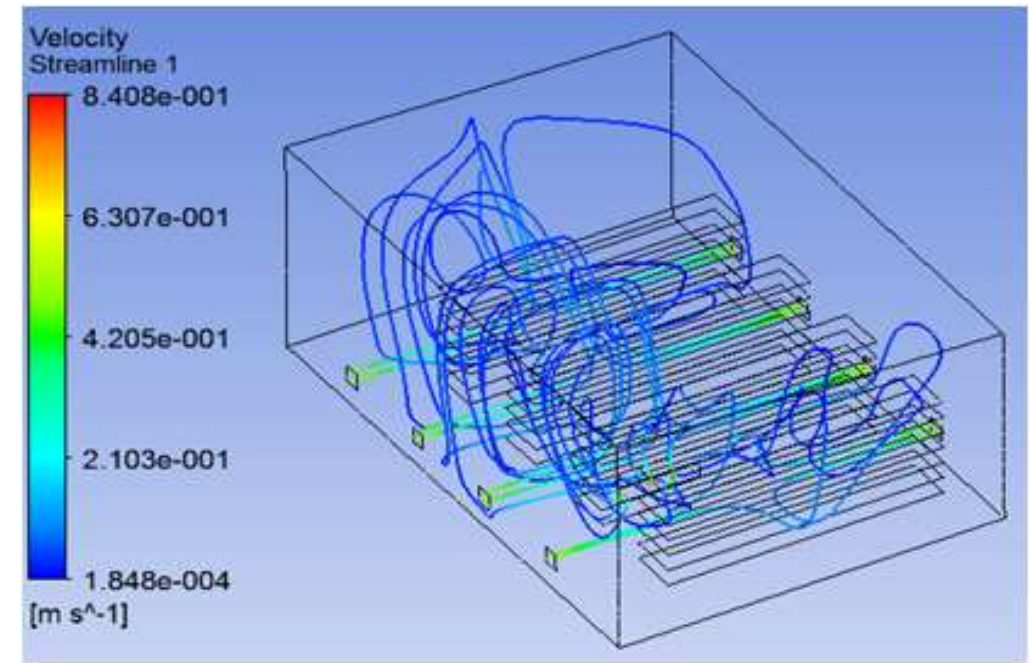

(a) Streamline Distribution (Diagonal View)

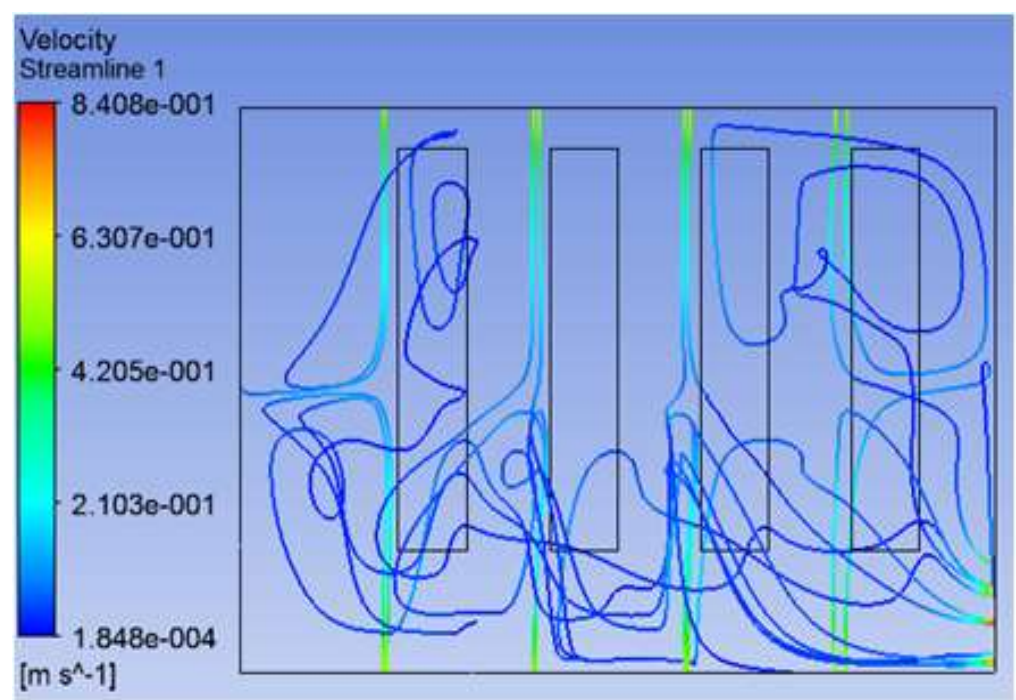

(b) Streamline Distribution (Top View)

Figure 8. Flow Characteristics of Case 3

Figure 10 shows the flow characteristics of Case 4 and Figure 11 shows the heat transfer characteristics of Case 4. As shown in Figure 10, the air blown by the FCUs flows inside to go out through the FANs. The velocity shows a distribution in a range of $0 \sim 0.84 \mathrm{~m} / \mathrm{s}$. As shown in Figure 11, the temperatures are high when the air is blown by the FCUs and heat was transferred to the entire space through convection. The temperatures showed a distribution in a range of $12.0 \sim 14.2{ }^{\circ} \mathrm{C}$. Air flows and heat transfer characteristics in smart farms were analyzed under four conditions. Case 1 showed a mean temperature of $12.983{ }^{\circ} \mathrm{C}$ and a standard deviation of 0.552 , Case 2 showed a mean temperature of $13.370{ }^{\circ} \mathrm{C}$ and a standard deviation of 0.465 , Case 3 showed a mean temperature of $13.438{ }^{\circ} \mathrm{C}$ and a 


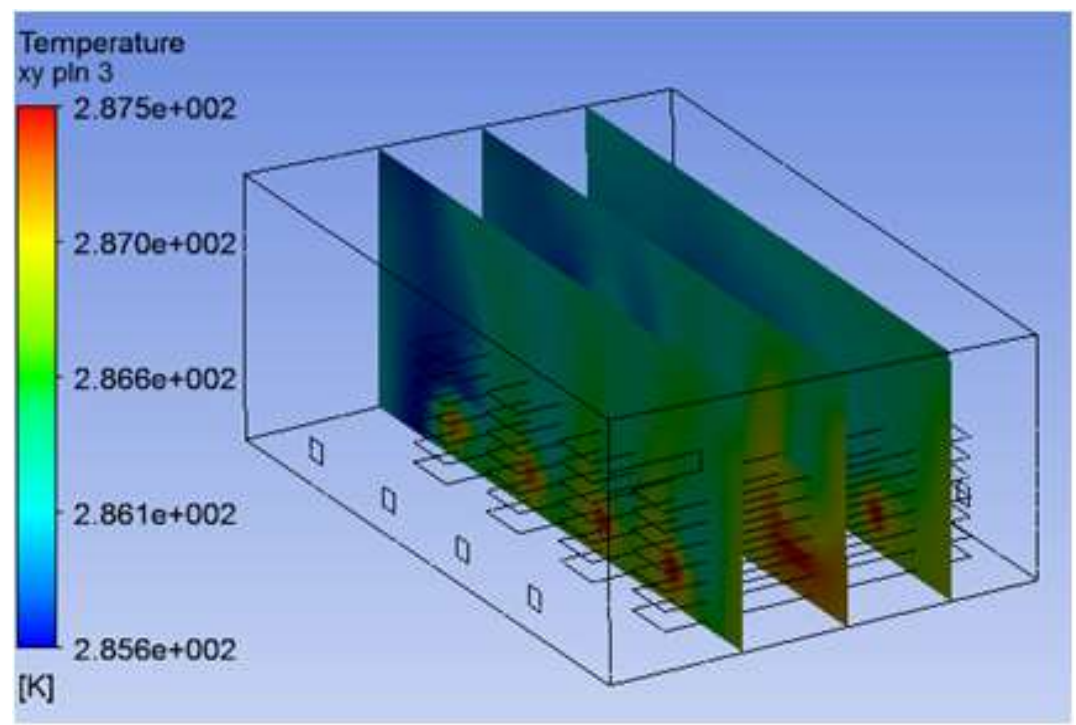

(a) Cross-sectional Temperature Distribution

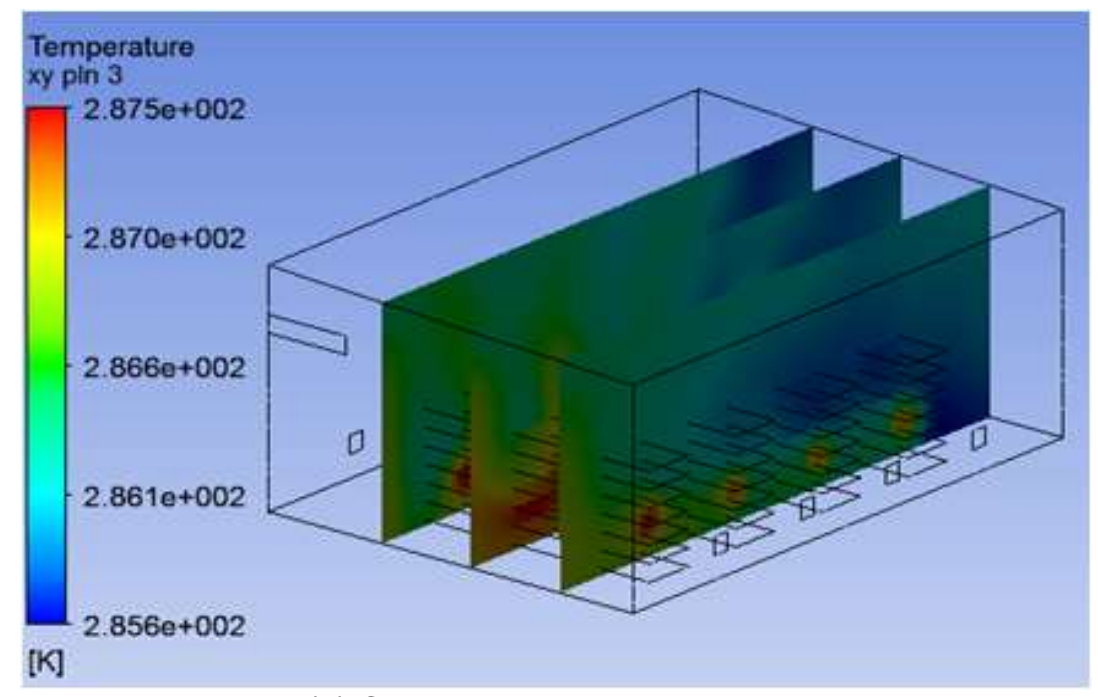

(b) Cross-sectional Temperature Distribution

Figure 9. Heat Transfer Characteristics of Case 3

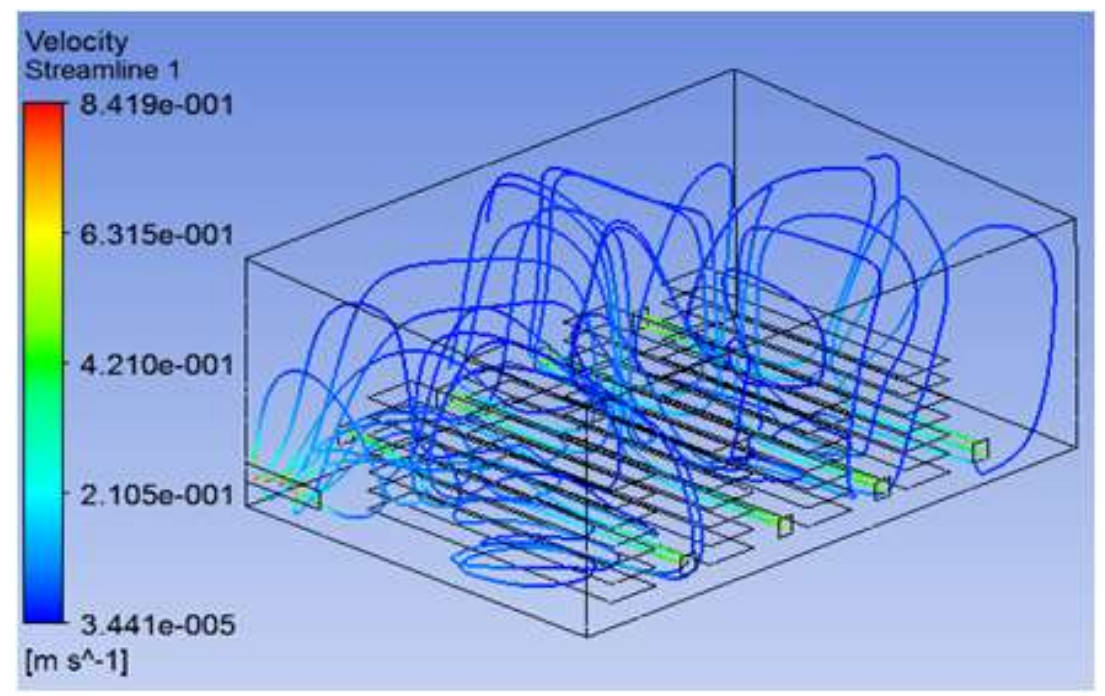

(a) Streamline distribution(diagonal view) 


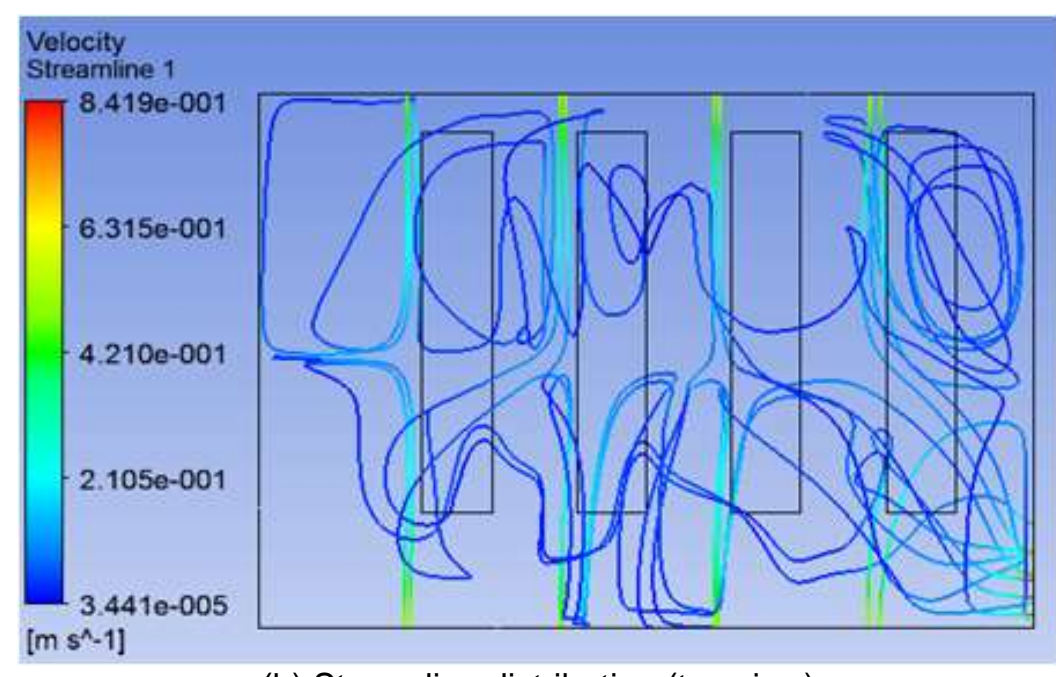

(b) Streamline distribution (top view)

\section{Figure 10. Flow Characteristics of Case 4}

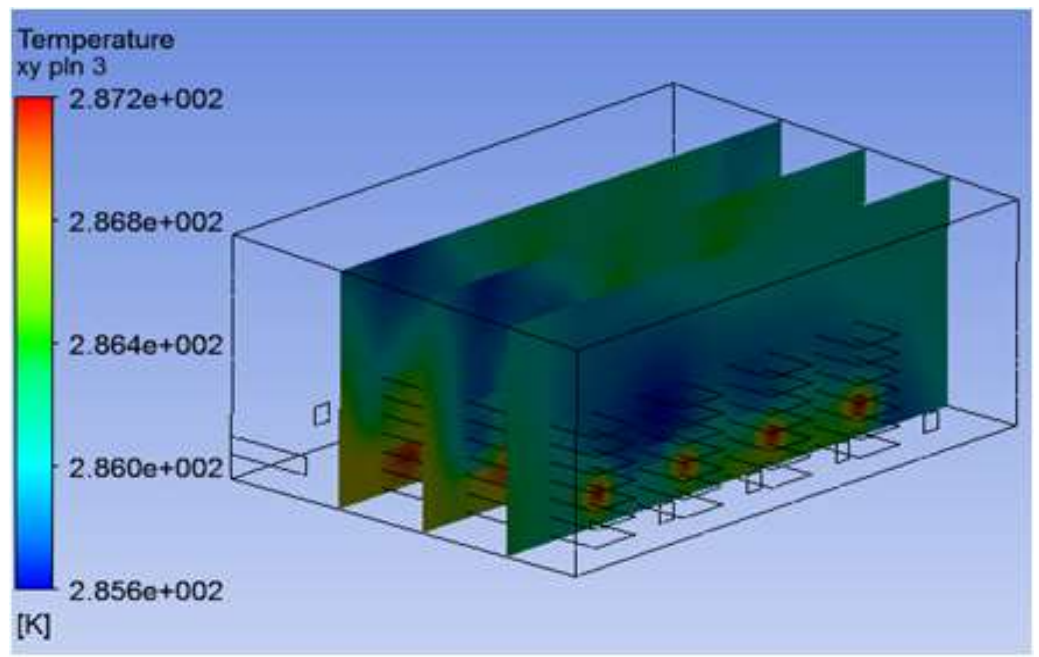

(a) Cross-sectional temperature distribution

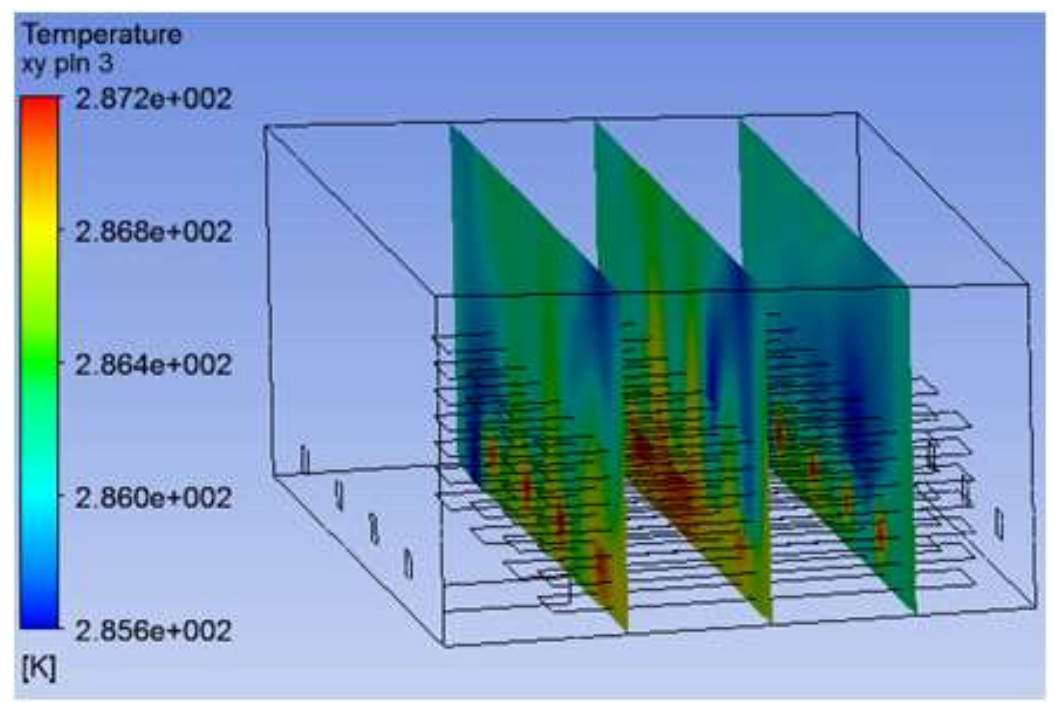

(b) Cross-sectional temperature distribution

Figure 11. Flow Characteristics of Case 4 
standard deviation of 0.338 , and Case 4 showed a mean temperature of $13.308{ }^{\circ} \mathrm{C}$ and a standard deviation of 0.298. Therefore, the standard deviation of Case 4 where the FCUs and FANs were positioned low was the lowest as 0.298 . Therefore, this smart farm is judged to be the optimum model because the temperatures around the shelves inside the smart farm become the most evenly distributed. However, Case 4 is shown to require excessive construction costs because of its structure. Since the primary role of FANs is ventilation and warm air always exists in the upper region, the relevant air should be discharge to prevent adverse effects on the crop. Among the results of analysis of flows of the four cases, those of Case 3 and Case 4 did not show any significant difference. Therefore, the application of Case 3 is also considered to show good results.

\section{Conclusions}

The smart mushroom cultivation equipment's internal fluid was assumed to be air. To analyze smart mushroom cultivation equipment at room temperature, the internal initial temperature was set to $10^{\circ} \mathrm{C}$ and it was assumed that air at $15^{\circ} \mathrm{C}$ would flow in through the FCUs at $0.5 \mathrm{~m} / \mathrm{s}$ and flowout through the FANs. The air flow velocity and heat transfer characteristics of the mushroom cultivation equipment were studied assuming that the internal temperature of smart would be constant in a range of $12 \sim 18^{\circ} \mathrm{C}$ to obtain the following conclusions.

(1) Case 1 showed a mean temperature of $12.983^{\circ} \mathrm{C}$ and a standard deviation of 0.552 , Case 2 showed a mean temperature of $13.370{ }^{\circ} \mathrm{C}$ and a standard deviation of 0.465 , Case 3 showed a mean temperature of $13.438^{\circ} \mathrm{C}$ and a standard deviation of 0.338 , and Case 4 showed a mean temperature of $13.308{ }^{\circ} \mathrm{C}$ and a standard deviation of 0.298 .

(2) The standard deviation of Case 4 where the FCUs and FANs were positioned low was the lowest as 0.298 . Therefore, this smart farm is judged to be the optimum model because the temperatures around the shelves inside the smart farm become the most evenly distributed.

(3) Case 4 is shown to require excessive construction costs because of its structure. Since the primary role of FANs is ventilation and warm air always exists in the upper region, the relevant air should be discharge to prevent adverse effects on the crop. Among the results of analysis of flows of the four cases, those of Case 3 and Case 4 did not show any significant difference. Therefore, the application of Case 3 is also considered to show good results.

(4) Hybrid smart mushroom cultivation equipment was implemented to produce uniform and high quality mushroom by controlling temperature, humidity and environment optimized for mushroom production.

\section{References}

[1] Sung-Taek Jeon1, Jin-Pyo Cho2, Separate type heat pipe performance comparison by the heat exchanger shapes, Journal of the Korea Academia-Industrial cooperation Society Vol. 17, No. 12 pp. 723-729, 2016

[2] Tae-Kwon Kim1, Ji-Soo Ha1, Yong-Seok Choi, A thermal-flow analysis of deaerator floor of power plant for reducing the radiative heat transfer effect, Journal of the Korea Academia-Industrial cooperation Society Vol. 17, No. 12 pp. 476-481, 2016

[3] Dae-Seok, Yean-Jung Kim, A Study on Priority of Policy for Smart Farming System Using AHP Approach, Journal of the Korea Academia-Industrial cooperation Society Vol. 17, No. 11 pp. 348-354, 2016

[4] H. G. Kang, " Study of Energy Management Strategy Considering Various Working Models of Plug-in Hybrid Electric Tractor”. Trans. Of KSME-B, Vol. 37 No. 2, pp. 181-186, 2013.

[5] Y. C. Kim, Measurement of Critical Heat Flux Using the Transient Inverse Heat Conduction Method in Spray cooling", . Trans. Of KSME-

[6] B, Vol. 40 No. 10, pp. 653-658, 2016.

[7] S. H. Lee, B. K. Yu, H. J. Kim, N. K. Yun, J. C. Jung, "Technology for Improving the Uniformity of the 
Environment in the Oyster Mushroom Cultivation House by using Multi-layered Shelves", Protected Horticulture and Plant Factory, Vol. 24, No. 2, pp. 128-133, June,

[8] 2015.

[9] J. B. You, Y. C. Kim, J. U Cho, "Thermal and Fluid Analyses of Inner Air at Decomposition Equipment on the Waste Gas of Perfluorinated Compounds", Journal of the Korea Academia-Industrial cooperation Society, Vol. 16, No. 2, pp. 1375-1380, 2015.

[10] J. U. Cho, B. S. Min, E. J Lee, J. S. Nam "Model Design by Structural Analysis of Vinyl House at Heavy Snow", Journal of the Korea Academia-Industrial cooperation Society, Vol. 11, No. 8, pp. 2727-2733, 2010.

[11] Breribach, J. and Kranzlin, F., Fungi of Switzerland vol. 3 Boletes and Agarics. pp. 312, 1991.

[12] Min Lee1, Tae-Wan Kim, A Study on the Heat Sink with internal structure using Peltier Module in the Forced Convection, Journal of the Korea Academia-Industrial

[13] cooperation Society Vol. 15, No. 6 pp. 3410-3415, 2014

[14] D. Y. Kim, J. M. Yang, J. R. Park, J. C.1 Woo, "Developing a Winder Controller for Greenhouse Winding Walls Sensing Temperature and Humidity", Korean Institute of Intelligent Systems, pp. 209210, 2013.

[15] Jae-Won Kim1, Jung-Ho Lee1, Chan-Hee Park, Research of shape optimization for High-Efficiency Electronic cold modules taking into consideration thickness and thermoelectric element mounting position, Journal of the Korea Academia-Industrial

[16] cooperation Society Vol. 16, No. 12 pp. 8350-8356, 2015

[17] Kyeong-Jung Yong1, Byung-Chul Lim1, Sang-Heup Park, Heat Flow Analysis of

[18] Inner Groove Tube for Latent Heat Exchanger in Condensing Gas Boiler, Journal of the Korea Academia-Industrial cooperation Society Vol. 15, No. 7 pp. 4052-4056, 2014

[19] Chang-Duk Jeon1, Dong-Seon Kim1, Seung-Jun Lee, Feasibility Study on a Defrost Control Method by Using a Photoelectric Sensors, Journal of the Korea Academia-Industrial cooperation Society

[20] Vol. 15, No. 6 pp. 3389-3395, 2014 
International Journal of $u-$ and e- Service, Science and Technology Vol.10, No.8 (2017) 